\title{
IDENTIFICAÇÃO DE BACTÉRIAS DIAZOTRÓFICAS ISOLADAS EM CULTIVARES DE PALMA (Opuntia e Nopalea) USANDO O GENE recA
}

\author{
IDENTIFICATION OF DIAZOTROPHS ISOLATED FROM PALM CULTIVARS \\ (Opuntia and Nopalea) USING THE recA GENE
}

\author{
Maria Luiza Ribeiro Bastos da SILVA ${ }^{1}$; Carolina dos Santos FIGUEIRÔA ${ }^{2}$; \\ Adália Cavalcanti do Espírito Santo MERGULHÃO ${ }^{3}$; \\ Maria do Carmo Catanho Pereira de LYRA ${ }^{4}$ \\ 1. Bióloga, Pós-doutoranda do PNPD/CAPES/FINEP do Instituto Agronômico de Pernambuco - Recife, PE. maria.luiza@ipa.br; 2. \\ Bióloga, Bolsista de apoio técnico CNPq; 3. Bióloga, Pesquisadora - IPA, Recife, PE; \\ 4. Engenheira Agrônoma, Pesquisadora- IPA, Recife, PE.
}

\begin{abstract}
RESUMO: Este trabalho teve como objetivo caracterizar filogeneticamente os isolados bacterianos da cultura da palma forrageira usando o gene recA. Para o isolamento caldódios de palma foram maceradas e inoculadas em meios semissólido semi-seletivo NFb, JNFb, LGI e LG sem adição de nitrogênio. Foram obtidos doze micro-organismos cuja a analise parcial do gene recA possibilitou a identificação dos gêneros Azospirillum, Bacillus e Methylobacterium.. Bactérias diazotróficas encontrados na cultura da palma podem ter uma grande função como bactéria promotora de crescimento. $\mathrm{O}$ gene recA mostrou-se bastante consistente para uso em filogenia molecular de bactérias. Observou-se ainda a presença de bactérias destes gêneros podem ter de grande interesse para futuros estudos considerando seu alto poder biotecnológico.
\end{abstract}

PALAVRAS-CHAVE: Diversidade. Endofíticos. Filogenia. Reação em cadeia da polimerase (PCR).

\section{INTRODUÇÃO}

A cultura da palma forrageira no Nordeste do Brasil tem uma grande importância econômica por ser o alimento principal dos animais na região semiárida. Há alguns anos esta cultura vem sofrendo com o ataque de um inseto chamado cochonilha do carmim (Dactylopius Opuntiae) que está devastando toda área plantada e causando prejuízos para os pequenos agricultores que vivem da cultura da palma para alimentação de seu rebanho.

Os micro-organismos endofíticos que estão presentes na cultura da palma forrageira, geralmente são fungos e bactérias, que interagem e vivem sistematicamente no interior dessas plantas, sem causar aparentemente danos aos seus hospedeiros. Existe uma série de razões para que se aprofundem os estudos com endofíticos, pois, vários deles são capazes de produzirem antibióticos e outros metabólicos secundários de interesse farmacológico, muitos têm sido usados como agentes de controle biológico de pragas e doenças e também como bioherbicidas (DÖBEREINER, 1997; CHEANG et al., 2005).

Genes usados para o estudo de filogenia de espécies têm um papel importante na identificação taxonômica principalmente quando se trata de espécies e gêneros relacionados (FELSENSTEIN, 2004; VINUESA et al., 2005). É interessante estabelecer que a filogenia de um único gene não deve ser confundida com a filogenia das espécies já que cada árvore formada com um único gene é o resultado aleatório de um processo genealógico único. Escobar-Páramo et al, (2004), observaram que nas comparações multilocus a identificação e remoção de sequiências submetidas a transferência lateral dentro e entre espécies pode interferir de forma crítica na filogenia de espécies principalmente quando múltiplos isolados são analisados. Alguns autores como Eisen (1995) e Young (1998), avaliaram o impacto da transferência de genes na interpretação da filogenia de um único gene, como aqueles com base na SSU (pequena subunidade ribossomal) em que se faz necessário estudar mais loci. Estes autores observaram dois loci $a t p \mathrm{D}$ e rec $\mathrm{A}$ em espécies representativas de rizóbio de crescimento rápido, e verificaram que as bactérias são consistentes com a SSU correspondente em sua filogenia. O gene recA codifica parte do gene da recombinação gênica e no sistema de reparo do DNA, além de possuírem seqüencias curtas que podem limitar a detecção de mosaicismos intragênicos, que são, fenômenos que ocorrem quando um indivíduo apresenta dois materiais genéticos distintos, causando uma falha genética através de mutação resultando em linhagens de células distintas geneticamente.

A falta de conhecimento sobre a ocorrência de bactérias endofíticas em plantas quanto a sua identidade, diversidade e os níveis populacionais nos diferentes tecidos das plantas é ainda um enigma para entender a intima relação que 
desenvolveram estes micro-organismos com a sua planta hospedeira (BAZZICALUPO; OKON, 2000; MELLONI et al., 2004). Além de possuírem uma habilidade para sobreviver dentro da planta com pouca ou nenhuma competição microbiana os tornam potenciais candidatos para o controle biológico. Atualmente, não há estudos sobre os endofíticos presentes na cultura da palma forrageira. Diante disto, este trabalho teve como objetivo caracterizar filogeneticamente os isolados bacterianos da cultura da palma forrageira usando o gene parcial recA.

\section{MATERIAL E MÉTODOS}

Foi coletado como amostra um cladódio de cada variedade de palma (Tabela 1); as amostras de cladódio foram cultivadas em meios de cultivo semissólidos, semisseletivos (NFb, JNFb, LGI e LG) e sem adição de nitrogênio, como descrito por Döbereiner et al. (1995). Para o isolamento, foram utilizados $10 \mathrm{~g}$ de cada amostra do cladódio (massa fresca), os quais foram lavados com água corrente, triturados e misturados em $90 \mathrm{~mL}$ de solução salina ( $\mathrm{NaCl}, 0,5 \%)$ e diluídos serialmente $\left(10^{1}-10^{7}\right)$. De cada diluição, foram retiradas alíquotas de $0,1 \mathrm{~mL}$ e inoculadas em frascos de vidro contendo os meios de cultura ( $\mathrm{NFb}, \mathrm{JNFb}$, LGI e LG); estes foram incubados a $30^{\circ} \mathrm{C}$ e o crescimento bacteriano foi avaliado aos três, cinco e sete dias, verificando-se o aparecimento ou não da película característica para as bactérias diazotróficas endofíticas. Após o completo isolamento de uma cultura pura, estes isolados foram crescidos em meio DYGS (RODRIGUES NETO et al., 1986) e foi realizada a extração de DNA genômico. Para identificar o provável gênero bacteriano foram realizadas extração de DNA usando o Kit Wizard Genomic DNA Purification (Promega) de acordo com as recomendações do fabricante. A amplificação do gene $r e c A$ foi realizado usando os primers recA-6F (5'-CGK CTS GTA GAG GAY AAA TCG GTG GA-3') e recA-555R (5'-CGR ATC TGG TTG ATG AAG ATC ACC AT-3') (GAUNT et al., 2001) e as condições de amplificação foi realizada em um volume final de $25 \mu$ l contendo: $40 \mathrm{ng}$ de DNA molde, $1 \mu \mathrm{M}$ de cada primer, $12,5 \mu \mathrm{L}$ de la
GoTaq Colorless (Promega). Os ciclos de temperaturas foram realizados em um termociclador PCT-100 ${ }^{\mathrm{TM}}$ (MJ Research, Inc, USA) com uma desnaturação inicial de $94^{\circ} \mathrm{C}$ por $4 \mathrm{~min}$., $30 \mathrm{~s} \mathrm{a} 94^{\circ} \mathrm{C}$, $30 \mathrm{~s}$ de anelamento a $50^{\circ} \mathrm{C}$ e $1 \mathrm{~min}$. de extensão a $72^{\circ} \mathrm{C}$, seguidos de uma extensão final de $8 \mathrm{~min}$. a $72^{\circ} \mathrm{C}$ por 30 ciclos.

Os produtos amplificados foram visualizados em eletroforese a $1 \%$ em gel de agarose usando tampão TBE $0,5 \mathrm{X}$, a 100 Volts. Os produtos foram visualizados usando SybrGold (Invitrogen) e fotodocumentados no LPIX-HE da Loccus do Brasil. Após a purificação (LYRA, 2001), os produtos amplificados foram seqüenciados na Macrogen Inc. Korea. As sequências obtidas foram alinhadas e comparadas pelo programa 'ClustalX V.4.0.' (LARKIN et al., 2007), com base no gene recA. Além disso, para esta comparação, foi realizada a busca de sequências depositadas no GenBank, com o propósito de agrupar as bactérias nos respectivos gêneros. Para matriz de distância das árvores filogenéticas, foi utilizado o método fenético baseado em distância genética neighborjoining (NJ) (SAITOU; NEI, 1987) e o algoritmo pdistance, respectivamente processado pelo programa Molecular Evolutionary Genetics Analysis-MEGA versão 4.0 (TAMURA et al., 2007). Todas as sequências do gene recA obtidas neste estudo foram enviadas ao banco de dados do NCBI (http://www.ncbi.nlm.nih.gov) e receberam os números de acesso: KC312318 a KC312329.

\section{RESULTADOS E DISCUSSÃO}

\section{Isolamento da bactéria diazotróficas}

Foram isolados doze microrganismos provenientes do interior dos cladódios de palma forrageira das regiões do agreste (Caruaru) e sertão de Pernambuco (Arcoverde) (Tabela 1). Rodríguez e Fraga (1999) relataram que os gêneros bacterianos que mais se destacam como promotores de crescimento são: Pseudomonas, Bacillus, Serratia, Azospirillum e Azotobacter. Estes dados corroboram com os resultados encontrados neste estudo onde foram isoladas bactérias diazotróficas endofíticas destes gêneros. 
Tabela 1: Resultados da busca por similaridade no NCBI GenBank dos isolados pelo seqüenciamento parcial do gene recA

\begin{tabular}{|c|c|c|c|c|c|c|c|c|}
\hline Legenda & Genbank & $\begin{array}{l}\text { Meio de } \\
\text { isolamento }\end{array}$ & $\begin{array}{c}\text { Variedade } \\
\text { de Palma/Local de } \\
\text { Coleta }\end{array}$ & Micro-organismo & $\begin{array}{l}\text { Homologia } \\
\text { NCBI }\end{array}$ & no & Identidade & E-value \\
\hline isolAM01 & KC312318 & $\mathrm{NFb}$ & $\begin{array}{l}\text { (1327) Marmillon } \\
\text { Fodder/Caruaru }\end{array}$ & $\begin{array}{l}\text { Azospirillum lipoferum } \\
\text { 4B (NC_016622.1) }\end{array}$ & $97 \%$ & & $100 \%$ & $5 e-125$ \\
\hline isolAM02 & KC312319 & LG & $\begin{array}{l}\text { (1327) Marmillon } \\
\text { Fodder/Caruaru }\end{array}$ & $\begin{array}{l}\text { Azospirillum lipoferum } \\
\text { 4B, (NC_016622.1 }\end{array}$ & $97 \%$ & & $100 \%$ & $7 e-125$ \\
\hline isolAM04 & KC312320 & $\mathrm{NFb}$ & $\begin{array}{c}\text { 27(1294) Mexico } \\
\text { Vegetable/Arcoverde }\end{array}$ & $\begin{array}{l}\text { Azospirillum lipoferum } \\
\text { 4B (NC_016622.1 }\end{array}$ & $100 \%$ & & $100 \%$ & $2 e-120$ \\
\hline isolAM05 & KC312321 & $\mathrm{NFb}$ & $\begin{array}{l}\text { 27(1294) Mexico } \\
\text { Vegetable/Arcoverde }\end{array}$ & $\begin{array}{l}\text { Azospirillum brasilense } \\
\text { Sp245 (NC_016617.1) }\end{array}$ & $99 \%$ & & $100 \%$ & $7 e-120$ \\
\hline isolAM06 & KC312322 & $\mathrm{JNFb}$ & $\begin{array}{l}\text { AM6 16-F21 (403) } \\
\text { Forrageira } \\
\text { México/Arcoverde }\end{array}$ & $\begin{array}{l}\text { Methylobacterium } \\
\text { radiotolerans } \\
\text { (NC_010505.1) }\end{array}$ & $91 \%$ & & $100 \%$ & $1 e-126$ \\
\hline isolAM20 & KC312323 & LGI & IPA 90-92/Caruaru & $\begin{array}{c}\text { Gluconacetobacter } \\
\text { diazotrophicus } \\
\text { PA15 (NC_011365.1) }\end{array}$ & $49 \%$ & & $100 \%$ & $4 e-06$ \\
\hline isolAM24 & KC312324 & $\mathrm{NFb}$ & $\begin{array}{l}\text { 422 CPTSA } 1281 \\
(2001800) / \text { Caruaru }\end{array}$ & $\begin{array}{l}\text { Bacillus pumilus SAFR- } \\
032 \text { (NC_009848.1) }\end{array}$ & $80 \%$ & & $89 \%$ & $6 e-72$ \\
\hline isolAM26 & KC312325 & $\mathrm{NFb}$ & $\begin{array}{l}\text { F3 Rojo Vigor - } \\
\text { Frutífera/Arcoverde }\end{array}$ & $\begin{array}{l}\text { Bacillus pumilus SAFR- } \\
032 \text { (NC_009848.1) }\end{array}$ & $94 \%$ & & $93 \%$ & 0.0 \\
\hline isolAM28 & KC312326 & $\mathrm{NFb}$ & $\begin{array}{l}\text { Palma de Espinho } \\
\text { Frutífera }\end{array}$ & $\begin{array}{c}\text { Methylobacterium } \\
\text { radiotolerans JCM } \\
2831 \text { (NC_010505.1) }\end{array}$ & $90 \%$ & & $95 \%$ & $6 e-115$ \\
\hline isolAM29 & KC312327 & $\mathrm{NFb}$ & $\begin{array}{l}\text { /Arcoverde51-1317 } \\
\text { Chile Fruit/Arcoverde }\end{array}$ & $\begin{array}{l}\text { Bacillus pumilus SAFR- } \\
032 \text { (NC_009848.1) }\end{array}$ & $92 \%$ & & $94 \%$ & 0.0 \\
\hline isolAM30 & KC312328 & $\mathrm{NFb}$ & $\begin{array}{c}43 \text { - Miúda } \\
\text { Tradicional/Arcoverde }\end{array}$ & $\begin{array}{l}\text { Bacillus pumilus SAFR- } \\
032 \text { (NC_009848.1) }\end{array}$ & $91 \%$ & & $92 \%$ & 0.0 \\
\hline isolAM36 & KC312329 & $\mathrm{JNFb}$ & $\begin{array}{c}\text { (438) F8 } \\
\text { Forrageira/Caruaru }\end{array}$ & $\begin{array}{l}\text { Bacillus pumilus SAFR- } \\
032\end{array}$ & $89 \%$ & & $91 \%$ & 0.0 \\
\hline
\end{tabular}


Oito do total de bactérias diazotróficas endofíticas foram provenientes do meio $\mathrm{NFb}$ (Azospirillum brasilense; A. lipoferum; Bacillus pumilus, Methylobacterium radiotolerans). Segundo Magalhães e Döbereiner (1984) mostraram mesmo sendo as espécies de Azospirillum - favorecidas nos meios $\mathrm{NFb}$, outros microrganismos diazotróficos podem crescer nestes meios, como ocorreu no presente estudo. O meio LG cresceu apenas um isolado que obteve homologia comAzospirillum brasilense) e no meio LGI, o isolado teve uma homologia muito baixa com Gluconacetobacter diazotrophicus PAl5 de 49\%.. Foram encontrados dois isolados no meio JNFb (Bacillus $e$ Methylobacterium) do total das bactérias diazotróficas isoladas. Apesar de descrito na literatura segundo Dobereiner (1997) que o meio
JNFb (Tabela 1) seja um meio para isolar Herbaspirullum, no nosso estudo, os isolados que cresceram neste meio foram: Methylobacterium radiotolerans e Bacillus pumilus (Figura 1). A falta de especificidade do meio $\mathrm{JNFb}$, já considerada por Baldani et al. (1999), indica que o meio JNFb permite o crescimento de outras bactérias endofíticas, principalmente aquelas capazes de tolerar a maior acidez inicial deste meio.

A diversidade da comunidade endofítica ainda tem muito a ser elucidada. Algumas bactérias diazotróficas como Acetobacter diazotrophicus, Herbaspirillum seropedicae, Azoarcus spp. e Azospirillum spp (CHAINTREUIL et al., 2000), antes descritas somente com localização na região de rizosfera, agora também são descritas em regiões endofíticas.

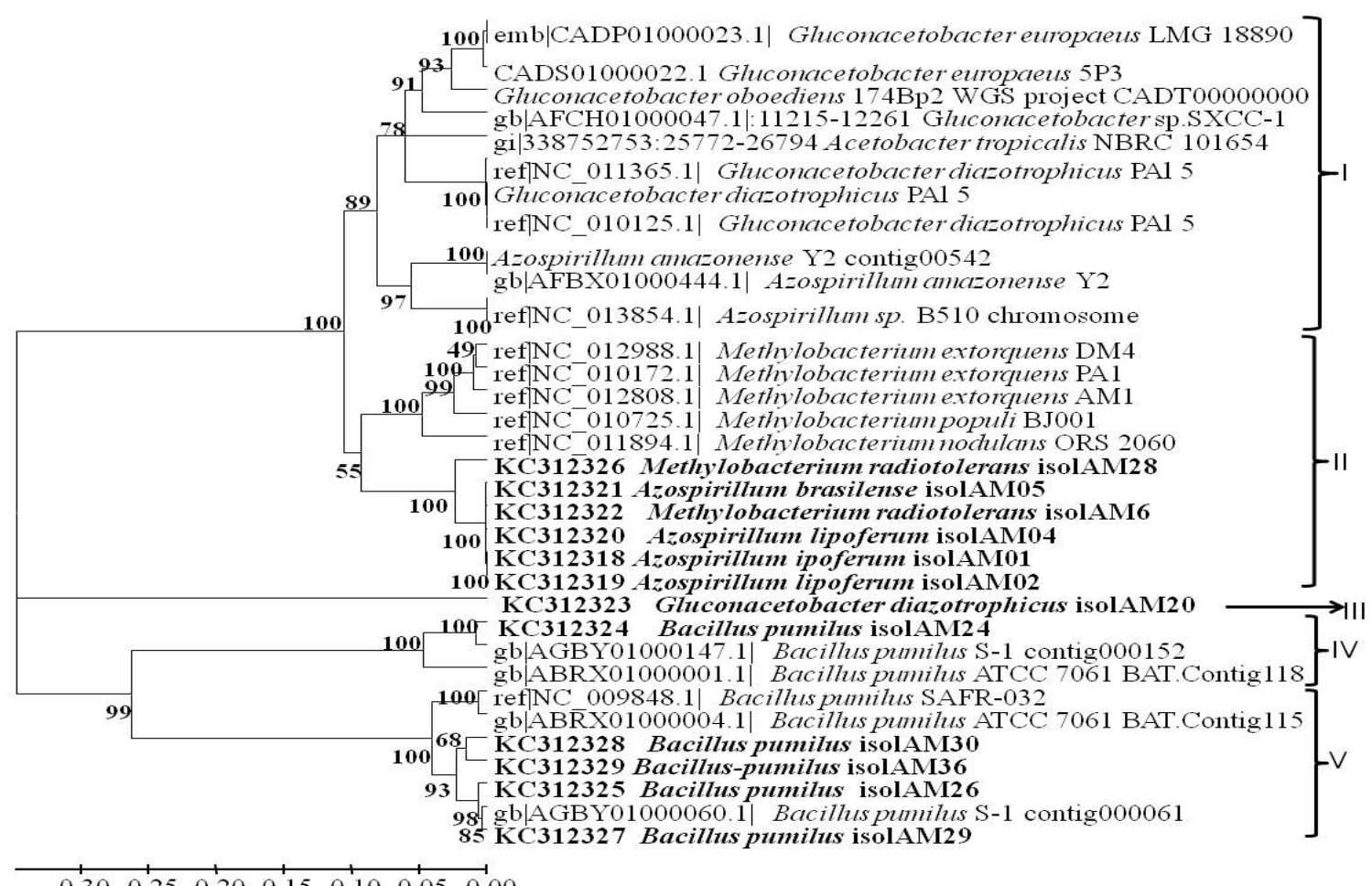

$\begin{array}{lllllll}0.30 & 0.25 & 0.20 & 0.15 & 0.10 & 0.05 & 0.00\end{array}$

p-distance

Figura 1. Dendrograma baseado na sequência do gene recA, mostrando as posições filogenéticas dos isolados em relação às sequências já depositadas em banco de dados. Os números internos representam a porcentagem de vezes em que foi possível reconstruir o agrupamento em questão. A régua é a distância de similaridade do agrupamento em questão.

\section{Análise e sequenciamento baseada no gene $\operatorname{rec} \mathrm{A}$}

A qualidade do DNA genômico isolado foi avaliada por meio de eletroforese em gel de agarose. Foi utilizado o padrão 100 pb DNA ladder
(Invitrogen) como padrão de tamanho molecular e o tamanho gerado pela amplifucação do gene recA foi de $700 \mathrm{pb}$. As seqüências do gene recA foram submetidas ao programa BLASTn do GenBank 
onde se realizou uma pesquisa cuja comparação ocorreu entre os dados obtidos neste trabalho com os que já se encontram no banco de dados. A análise por clusterização baseada nas sequências do gene recA permitiu um agrupamento mais congruente entre todos os gêneros distribuídos no dendrograma, porque os isolados estudados neste trabalho ficaram agrupados de acordo com suas espécies, mostrando que este gene tem uma capacidade de determinar a posição taxonômica de novos isolados segundo mostrado por Scholz et al. (2008) (Figura 1).

De acordo com análise comparativa foram formados cinco grupos. O grupo I formado apenas por sequencias de bactérias retiradas do GenBank, dos gêneros Gluconacetobacter e Azospirilum. O grupo II formado pelas sequências dos isolados (isolAM01, isolAM02, isolAM04 e isolAM05) que apresentaram elevada homologia ao gênero Azospirilum, mas separadas em ramos diferentes. $\mathrm{O}$ grupo III e IV foi formado pelos isolados (isolAM20 e isolAM24) respectivamente. Já o grupo $\mathrm{V}$ foi representado pela seqüência dos isolados (isolAM26, isolAM29, isolAM30 e isolAM36) apresentaram elevada homologia com o gênero Bacillus. O predomínio dos gêneros Bacillus e Azospirillum corrobora com os resultados obtidos por (LALANDE et al., 1989).

Os resultados entre as sequencias obtidas em relação às do banco de dados apresentaram entre $80-100 \%$ de similaridade, o que indica confiabilidade para os resultados encontrados.
Apenas o isolado isolAM20 (Gluconacetobacter diazotrophicus) apresentou uma baixa homologia com 49\% com as sequencias de bactérias diazotrófica endofítica. Segundo Payne et al. (2006) e Scholz et al. (2008), o gene recA, permite melhor discriminação do que o gene $16 \mathrm{~S}$ rDNA e genes rrs (Ribossomais). Entretanto, as análises obtidas do gene $r e c A$ não são exatamente semelhantes às obtidas pela filogenia da sequência do gene $16 \mathrm{~S}$ rDNA, indicando maior grau de resolução entre espécies relacionadas.

\section{CONCLUSÕES}

$\mathrm{O}$ sequenciamento parcial do gene recA mostrou-se eficiente para o estudo filogenético de bactérias em palma forrageira. A presença dos gêneros Azospirillum, Bacillus e Methylobacterium pode ser de grande interesse para futuros estudos, uma vez, que estes gêneros apresentam grande potencial biotecnológico.

\section{AGRADECIMENTOS}

Ao Instituto Agronômico de Pernambuco IPA, pela estrutura física e a Coordenação de Aperfeiçoamento de Pessoal de Nível Superior CAPES (PNPD - n ${ }^{\circ}$. 02714/09-4 Linha MCT/ FINEP), e á Fundação de Amparo à Ciência e Tecnologia de Pernambuco (FACEPE) pelo suporte financeiro concedido.

\begin{abstract}
This study aimed to characterize phylogenetically isolated bacterial culture of Cactus Pear using the parcial gene recA. For isolation cladodes were macerated and inoculated in semi-selective semisolid media NFB, $\mathrm{JNFb}$, LGI and LG without added nitrogen. Twelve micro-organisms were obtained whose analysis of partial gene recA enabled the identification of the genera Azospirillum, Bacillus and Methylobacterium. Diazotrophic bacteria found in the culture of Cactus Pear may have a great function as growth-promoting bacteria. The partial gene recA was shown to be quite consistent for use in molecular phylogeny of bacteria. We also observed the presence of bacteria of these genera may be of great interest for future studies considering its high power biotechnology.
\end{abstract}

KEYWORDS: Diversity. Endophytic. Phylogeny. PCR. DNA.

\title{
REFERÊNCIAS
}

BALDANI, J. I.; AZEVEDO, M. S.; REIS, V. M.; TEIXEIRA, K. R. S.; OLIVARES, F. L.; GOI, S. R.; BALDANI, V. L. D.; DOBEREINER, J. Fixação biológica de nitrogênio em gramíneas: avanços e aplicações. In: SIQUEIRA, J. O.; MOREIRA, F. M. S.; LOPES, A. S.; GUILHERME, L. R. G.; FAQUIN, V.; FURTINI NETO, A. E.; CARVALHO, J. G., eds. Inter-relação fertilidade, biologia do solo e nutrição de plantas. Viçosa, SBCS/UFLA/DCS, 1999. p. 621-666.

BAZZICALUPO, M.; OKON, Y. Associative and endophytic symbiosis. In: PEDROSA, F.; HUNGRIA, M.; YATES, M. G.; NEWTON, W. E., eds. Nitrogen fixation: from molecules to crop productivity. Dordrecht, Kluwer Academic Publishers. p. 409-410. 2000. 
CHAINTREUIL, C.; GIRAUD, E.; PRIN, Y.; LORQUIN, J. BÂ, A.; GILLIS, M.; LAJUDIE, P.; DREYFUS, B. Photosynthetic Bradyrhizobia Are Natural Endophytes of the African Wild Rice Oryza breviligulata. Applied and Environmental Microbiology, Washington, v. 66, n. 12, p. 5437-5447. 2000. http://dx.doi.org/10.1128/AEM.66.12.5437-5447.2000

CHEANG, A. J. R.; CERÓN, I. D. T.; BRINGAS, Y. F.; BADÍA, M. M. R.; CASTAÑEDA, J. M.; PÉREZ, M. H. Caracterización fisiológica de la comunidad microbiana endófita de la caña de azúcar. Revista Colombiana de Biotecnología, v. 1. p. 66-75. 2005.

DÖBEREINER, J. Biological nitrogen fixation in the tropics: social and economic contributions. Soil Biology and Biochemistry, v. 29, p. 771-774. 1997. http://dx.doi.org/10.1016/S0038-0717(96)00226-X

DOBEREINER, J.; BALDANI, V.L.D.; BALDANI, J. I. Como isolar e identificar bacterias diazotróficas de plantas não-leguminosas. - Brasília: EMBRAPA-SPI: Itaguai, RJ: EMBRAPA-CNPAB. 1995. 60p.

EISEN, J. A. The RecA protein as a model molecule for molecular systematic studies of bacteria: comparison of trees of RecAs and 16S rRNAs from the same species. Journal of Molecular Evolution, v. 41, p. 11051123. 1995. http://dx.doi.org/10.1007/BF00173192

ESCOBAR-PÁRAMO, A. P.; SABBAGH, P.; DARLU, O.; PRADILLON, C.; VAURY, G.; LECOINTRE, DENAMUR. E. Decreasing the effects of horizontal gene transfer on bacterial phylogeny: the Escherichia coli case study. Molecular Phylogenetic Evolution, v. 30, p. 243-250. 2004. http://dx.doi.org/10.1016/S10557903(03)00181-7

FELSENSTEIN, J. Inferring phylogenies, Sinauer Associates, INC, Sunderland, MA, 2004, p. 664.

GAUNT, M. W.; TURNER, S. L.; RIGOTTIER-GOIS, L.; LLOYD-MACGILPS, S. A.; YOUNG, J. P.W. Phylogenies of atpD and recA support the small subunit rRNA-based classification of rhizobia International Journal of Systematic and Evolutionary Microbiology, v. 51, p. 2037-2048. 2001. http://dx.doi.org/10.1099/00207713-51-6-2037

LALANDE, R.; BISSONNETTE, N.; COUTLEÉ, D.; ANTOUN, H. Identification of rhizobacteria from maize and determination of their plant-growth promoting potencial. Plant and Soil, v. 115, p. 7-11, 1989. http://dx.doi.org/10.1007/BF02220688

LARKIN, M. A.; BLACKSHIELDS, G.; BROWN, N. P.; CHENNA, R. McGETTIGAN, P. A.; McWILLIAM, H. VALENTIN, F.; WALLACE, L. M.; WILM, A.; LOPEZ, R.; THOMPSON, J. D.; GIBSON, T. J.; HIGGINS, D. G. I Clustal W and Clustal X version 2.0. Bioinformatics, Oxford, v. 23, n. 21, p. 2947-2948, 2007. http://dx.doi.org/10.1093/bioinformatics/btm404

LYRA, M. C. C. P. Estudios genéticos y fisiológicos del gen nolT de la región específica de cultivar, nolXWBTUV, de la bacteria de amplio rango de nodulación HH103 y sus implicaciones en el Sistema de Secreción de Tipo III (TTSS). 2001. 159 f. Tese (Doutorado em Biologia)-Facultad de Biología, Universidad de Sevilla, Sevilla, 2001.

MAGALHÃES, F. M. M.; DÖBEREINER, J. Ocorrência de Azospirillum amazonense em alguns ecossistemas da Amazônia. Revista de Microbiologia, São Paulo, v. 15, p. 246-252, 1984.

PAYNE, G. W.; RAMATTE, A.; ROSE, H. L.; WEIGHTMAN, A. J.; JONES, T. H.; TIEDJE, J. M. MAHENTHIRALINGAM, E. Application of a recA gene-based identification approach to the maize rhizosphere reveals novel diversity in Burkholderia species. FEMS Microbiology Letters, Holanda, v. 259, p. 126-132, 2006. 
RODRIGUES NETO, J.; MALAVOLTA JÚNIOR, V. A.; VICTOR, O. Meio simples para o isolamento e cultivo de Xanthomonas campestris pv. citri tipo B. Summa Phytopathologica, Campinas, v. 12, n. 1-2, p. 16. 1986.

RODRÍGUEZ, H.; FRAGA, R. Phosphate solubilizing bactéria and their role in plant growth promotion. Biotechnology Advances, Waterloo, v. 17, p. 319-339, 1999. http://dx.doi.org/10.1016/S0734-9750(99)000142

SAITOU, N.; NEI, M. The neighbor-joining method: a new method for constructing phylogenetic trees. Molecular Biology and Evolution, Chicago, v. 4, n. 4, p. 406-25, 1987.

SCHOLZ, H. C.; AL DAHOUK, S.; TOMASO, H.; NEUBAUER, H.; WITTE, A. SCHOTER, M.; KAMPFER, P.; FALSEN, E.; PFEFFER, M.; ENGEL, M. Genetic diversity and phylogenetic relationships of bacteria belonging to the Ochrobactrum-Brucella group by recA and 16S rRNA gene-based comparative sequence analysis. Systematic Applied Microbiology, West chester, v. 31, n. 1, p. 1-16. 2008.

TAMURA, K.; NEI, M.; KUMAR, S. MEGA 4: Molecular Evolutionary Genetics Analysis (MEGA) Software Version 4.0. Molecular Biology Evolutionary, Oxford, v. 24, n. 8, p. 1596-1599, 2007.

http://dx.doi.org/10.1093/molbev/msm092

VINUESA P.; SILVA, C., LORITE , M. J.; IZAGUIRRE-MAYORAL, M. L.; BEDMAR, E. J.; MARTINEZROMERO, E. Molecular systematics of rhizobia based on maximum likelihood and Bayesian phylogenies inferred from rrs, atpD, recA and nifH sequences, and their use in the classification of Sesbania microsymbionts from Venezuelan wetlands Systematic and Applied Microbiology, v. 28, p. 702-716, 2005. http://dx.doi.org/10.1016/j.syapm.2005.05.007

YOUNG, J. P. W. Bacterial evolution and the nature of species. In Advances in Molecular Ecology, p. 119131. Edited by G. R. Carvalho. Amsterdam: IOS Press. 1998. 